\title{
Chopped Strand/Plain Weave E-Glass as Reinforcement in Vacuum Bagged Epoxy Composites
}

\author{
Srinivas Shenoy Heckadka, Suhas Yeshwant Nayak, Karan Narang, and Kirti Vardhan Pant \\ Department of Mechanical and Manufacturing Engineering, Manipal Institute of Technology, Manipal University, \\ Manipal 576104, India \\ Correspondence should be addressed to Suhas Yeshwant Nayak; synayak@gmail.com
}

Received 26 June 2015; Revised 29 August 2015; Accepted 31 August 2015

Academic Editor: Hak Yong Kim

Copyright (C) 2015 Srinivas Shenoy Heckadka et al. This is an open access article distributed under the Creative Commons Attribution License, which permits unrestricted use, distribution, and reproduction in any medium, provided the original work is properly cited.

\begin{abstract}
Polymer matrix composites are one of the materials being extensively researched and are gaining a lot of importance due to advantages like high specific strength, greater flexibility in design, and reduced cost of manufacturing. In this study, tensile, flexural, impact, and interlaminar shear strength of chopped strand/plain weave E-glass composites were considered. Composite laminates with different stacking sequence were fabricated using Vacuum Assisted Resin Infusion Moulding (VARIM) technique. Fiber volume fractions (FVF) of 22\%, 26\%, and 30\% were adopted. Experiments were conducted in accordance with ASTM standards. Results indicate that laminates with three layers of plain weave mat exhibited better tensile, flexural, and interlaminar shear strength. However, laminates with two layers of chopped strand mat and one layer of plain weave mat showed improved impact resistance. In addition, scanning electron microscopy was used to analyze the fracture surface.
\end{abstract}

\section{Introduction}

One of the developments that transpired the engineering material scenario due to their excellent mechanical properties while being light weight, low cost, and highly flexible is a composite material. Composite basically constitutes a matrix which surrounds the reinforcement thus offering the required strength and durability that is necessary in a particular field of application. Chopped strand mats (CSM) are randomly oriented, provide excellent strand integrity, good wettability, and dispersion, and display even strength consideration in all directions. CSM are comparatively less expensive and exhibit low potency when compared to plain weave. CSM are mainly used for smaller mould and pattern making, bathroom units, partition boards, and water proofing. Alternatively fabrics such as plain weave $(\mathrm{PW})$ are spun into yarns having $\left[0^{\circ} / 90^{\circ}\right]$ orientation. These fabrics demonstrate highest resistance to deformation when loaded parallel to axis and least endurance when loaded perpendicular. Plain weave fabrics are easily pliable and offer low moisture absorption and high strength in specific directions and thus are used in manufacturing of boat hulls, structural panels, locomotive and automotive interiors, and parts like seals, wheels, bushings, and gears [1-3]. Matrix material such as epoxy provide exceptional adherence to chopped strand mat and plain weave fabrics thus make it most suitable for developing composite structures. Epoxy offers features like resistance to environmental degradation and good fibre adhesion and is also economical from production point of view [4].

Serna Moreno and Martínez Vicente [5] evaluated the in-planer shear strength and failure behavior of chopped glass reinforced polyester composites subjected to tensile and compression loads. Experimental data were compared with the findings from analytical predictions such as maximum stress and strain theory and Tsai-Hill and Tsai-Wu failure theories. Serna Moreno et al. [6] experimentally determined the stress strain failure aspects of a chopped glass reinforced polyester composites subjected to biaxial loading. Specimens with different geometries and loading conditions were utilized to estimate the failure modes. Results indicated that loading conditions and composite geometries significantly influenced the stress strain failure fields. Sarikanat et al. [7] investigated the influence of oligomeric siloxane on wetting of glass fibres with polyester resin. They observed that the 
greatest strength of composites is achieved when the composites were loaded in the direction of fibre orientation. An increase in tensile, flexural, and interlaminar shear strength with increase in concentration of oligomeric siloxane due to improved wettability was reported by the authors. Arifin et al. [8] studied the tensile properties of notched and unnotched epoxy and polyester composites reinforced with chopped strand mat and plain weave mat by varying the stacking sequence and number of layers. They concluded that polyester and epoxy composites had similar mechanical characteristics but unnotched specimens were stronger than the notched ones. Yasar et al. [9] in their study concluded that polyester and gelcoat content in composites had a significant influence on their tensile and fatigue properties. They noticed that the tensile properties improved with increase in gelcoat content while fatigue properties suffered.

Rafiquzzaman et al. [10] in their study on epoxy composites reinforced with alternate layers of chopped strand and plain weave mat concluded that introduction of a hole induced stress concentration in the specimen and weakened it. Dolati et al. [11] compared impact strengths of composites fabricated with epoxy and glass fibres in three different forms, namely, unidirectional, plain weave, and chopped strand mat. They observed that composites with chopped strand mat displayed superior resistance to damage extension when subjected to single and repeated high velocity impact test with ice projectiles.

El-Tayeb et al. [12] investigated the tribological properties of CSM 450-R-glass fibre reinforced polyester composites. Pin-on-disc arrangement with dry sliding contact condition was adopted to determine friction and wear maps. Chopped glass mat in three directions, namely, parallel, antiparallel, and normal, was considered. Test parameters such as sliding distances, sliding speeds, and applied loads were studied. Maximum wear was observed in normal direction and was least in antiparallel direction. Fernberg and Berglund [13] studied the fracture properties of chopped strand mat and sheet moulding compound reinforced polyester laminates. Bridging law concept was used to describe the fracture features of the composites.

Tshai et al. [14] investigated the mechanical properties of chopped strand E-glass and empty fruit bunch palm reinforced polylactide acid composites. Composites were fabricated by solution casting followed by palletization and hot compression. A constant fibre volume fraction of $20 \%$ was utilized with varying ratios of chopped strand E-glass and empty fruit bunch palm fibres. Addition of chopped strand E-glass fibres improved the strength and performance of composites. Prachasaree et al. [15] studied the parawood particle composite boards for their mechanical characteristics and resistance to moisture with varying percentage of cement, water, and calcium chloride and parawood particle reinforced with bidirectional glass fabrics of $\left[0^{\circ} / 90^{\circ}\right]$ orientation. Composite boards fabricated were exposed to wetdry cycles for simulating accelerated aging effects in order to assess the flexural durability and moisture resistance. Better strength and moisture resistance were observed in parawood particle reinforced with bidirectional glass fabrics. Arifin et al. [16] evaluated and compared the impact strength of chopped strand mat-woven roving-foam Klegecell reinforced epoxy/polyester composites. Different design configurations, namely, energy absorption, deflection, contact load, and damage patterns, were considered. Laminates were molded using hand lay-up technique. Epoxy blended composites performed better than polyester laminates. Shokrieh et al. [17] studied the influence of multiwalled carbon nanotubes on the mechanical properties of chopped strand mat reinforced polyester composites. Burn-off test was adopted to envision the dispersion state of carbon nanotubes. Addition of carbon nanotubes enhanced the strength aspects of the composites.

In the present study, epoxy based composites reinforced with chopped strand mat (CSM) and plain weave fabric (PW) are fabricated using VARIM technique and mechanical properties like tensile, flexural, interlaminar shear, and impact strength are studied and analyzed. Four combinations of CSM and PW mats were considered. This work was carried to explore the potential of using CSM/PW reinforced epoxy composites as an alternative material for building monocoque chassis for Formula One cars.

\section{Experimental Details}

2.1. Materials. E-glass fibres in the form of chopped strand and plain weave mats were used as reinforcing material. The areal densities of the chopped strand and plain weave mats were $450 \mathrm{gsm}$ and $631 \mathrm{gsm}$, respectively. The weaving in the case of plain weave mat was balanced with fibres equally distributed in warp and fill direction. The resin and hardener used in the composites were Epoxy Bi-sphenol-12 (LapoxL12) and Triethylene Tetro Amine (Lapox K6), respectively. The density of the resin and hardener is $1.162 \mathrm{gm} / \mathrm{cm}^{3}$ and $0.954 \mathrm{gm} / \mathrm{cm}^{3}$, respectively [18].

2.2. Fabrication of Composites. VARIM process was used to fabricate the composite panels of $300 \mathrm{~mm} \times 300 \mathrm{~mm}$. Vacuum-infusion method was adopted since it offers more benefits than hand lay-up method resulting in stronger and lighter laminates [19]. Releasing agent was applied on the mould to facilitate easy removal of the part after curing. The reinforcement mats were cut according to the requirement and placed in position using a masking tape. The number of layers and stacking sequence is presented in Table 1. Tacky tape was used around the periphery of the mould to hold the vacuum bag in position. A layer of peel ply and infusion mesh was put up next. Infusion mesh ensures even distribution of the resin. Connectors were used to connect the vacuum pump and resin inlet to the mould. A vacuum bagging film was used to pack the mould by sticking the bag using the tacky tape. Resin was fed by applying vacuum which flows at a constant rate throughout the fibres. Curing was done at ambient temperature and atmospheric pressure for duration of 24 hours. The part was then released and trimmed to remove the wavy edges. The thickness of the composite laminate was $3 \mathrm{~mm}$. Figure 1 shows the cured polymer composite panel.

2.3. Experimental Methods. Specimens for all the tests were cut from the cured panels by water jet cutting. Tensile strength was evaluated by conducting tensile test according 


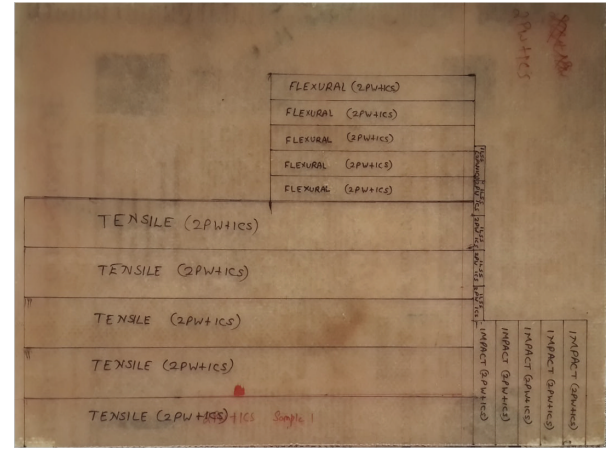

FIgURE 1: Composite panel.

TABLE 1: Designation and stacking sequence of E-glass fabric.

\begin{tabular}{lcc}
\hline Designation & Number of layers & Stacking sequence (lay-up) \\
\hline $3 \mathrm{PW}$ & 3 & {$[\mathrm{PW} / \mathrm{PW} / \mathrm{PW}]$} \\
$2 \mathrm{PW}+1 \mathrm{CSM}$ & 3 & {$[\mathrm{PW} / \mathrm{CSM} / \mathrm{PW}]$} \\
$1 \mathrm{PW}+2 \mathrm{CSM}$ & 3 & {$[\mathrm{CSM} / \mathrm{PW} / \mathrm{CSM}]$} \\
$3 \mathrm{CSM}$ & 3 & {$[\mathrm{CSM} / \mathrm{CSM} / \mathrm{CSM}]$} \\
\hline
\end{tabular}

to ASTM D3039 [20] on a Zwick Roell make (model: Zwick Roell Z020, Load Cell $20 \mathrm{kN}$ ) Universal Testing Machine (UTM) at a constant cross head speed of $2 \mathrm{~mm} / \mathrm{min}$. The test specimen dimensions were $250 \times 25 \times 3 \mathrm{~mm}$. Threepoint bending of ASTM D7264 [21] was adopted to determine the flexural strength of the composites on an Instron UTM (model: Instron 3366) at a constant cross head speed of $2 \mathrm{~mm} / \mathrm{min}$. The dimensions of the flexural test specimen were $116 \times 13 \times 3 \mathrm{~mm}$. To determine the impact strength of the laminates, Izod impact tests were conducted. The tests were conducted on a Zwick Roell make pendulum impact tester (model: Zwick Roell, HIT 50P) according to ASTM D256 [22]. The dimensions of the specimens were $64 \times 13 \times 3 \mathrm{~mm}$. The specimens were subjected to impact energy of $5.5 \mathrm{~J}$ at a theoretical velocity of $3.5 \mathrm{~m} / \mathrm{s}$. Shear strength was assessed by conducting short beam bending tests on the same Instron UTM. Dimensions of the specimens were $18 \times 6 \times 3 \mathrm{~mm}$. Three-point bending according to ASTM D2344 [23] was adopted.

For all the tests, five specimens from each panel were considered. Figure 2 presents the test specimens. The fracture surface of the composite specimen was examined using a Zeiss make scanning electron microscope (model: Zeiss EVO 18 , Germany). The samples were coated with a thin layer of silver by ion sputtering to prevent charging of the specimen. An accelerating voltage of $15 \mathrm{kV}$ was used. Probe current for the analysis was varied in the range of $145 \mathrm{pA}$ to $175 \mathrm{pA}$. The SEM micrographs were used to study the damage mode and fracture characteristics.

\section{Results and Discussion}

3.1. Mechanical Properties of Composites. The variation in tensile strength is shown in Figure 3. Among all the combinations, the best tensile strength was obtained for $3 \mathrm{PW}$ panels with 30\% FVF. Least tensile strength was observed in panel fabricated with 3 CSM and $22 \%$ fibre content. Increase in tensile strength was observed with increase in fibre volume fraction. In case of $3 \mathrm{PW}$ composite panels, there was a $21 \%$ increase in tensile strength as the fibre content was increased from $22 \%$ to $30 \%$. For composites with $2 \mathrm{PW}+$ 1CSM combination, increase in tensile strength was of the order of $19 \%$. Similarly, for the other two composite panels, the increase in tensile strength was in the range of 18 to $22 \%$.

Figure 4 presents the variation in flexural strength. It was observed that the highest flexural strength was achieved for 3PW panels with 30\% FVF. Least flexural strength was noticed in panel fabricated with 3CSM and 22\% fibre content. Increase in flexural strength was observed with increase in fibre volume fraction except in the panel with $2 \mathrm{PW}+1 \mathrm{CSM}$ where the strength reduced marginally when fibre content was increased from $26 \%$ to $30 \%$. In case of $3 \mathrm{PW}$ composite panels, there was a $28 \%$ increase in flexural strength as the fibre content was increased from $22 \%$ to $30 \%$. For composites with $2 \mathrm{PW}+1 \mathrm{CSM}$ fabric, increase in flexural strength was of the order of $24 \%$. Similarly, for the other two composite panels, the increase in flexural strength was in the range of 26 to $28 \%$.

The variation of impact strength is shown in Figure 5. Among all the combinations, the maximum impact strength was obtained for $1 \mathrm{PW}+2 \mathrm{CSM}$ panels with $30 \%$ FVF. Least impact strength was observed in panel fabricated with $2 \mathrm{PW}$ $+1 \mathrm{CSM}$ and $22 \%$ fibre content. Increase in impact strength was observed with increase in fibre volume fraction. In case of $1 \mathrm{PW}+2 \mathrm{CSM}$ composite panels, there was a $22 \%$ increase in impact strength as the fibre content was increased from $22 \%$ to $30 \%$. For composites with $3 \mathrm{CSM}$ fabric, increase in impact strength was of the order of $18 \%$. Similarly, for the other two composite panels, the increase in impact strength was in the range of 19 to $22 \%$.

Figure 6 presents the variation in short beam strength. It was observed that the peak interlaminar shear strength was noticed for 3PW panels with 30\% FVF. Least short beam strength was observed in panel fabricated with 3CSM and $22 \%$ fibre content. Increase in resistance to shear was observed with increase in fibre volume fraction. In case of $3 \mathrm{PW}$ composite panels, there was a $22 \%$ increase in shear strength as the fibre content was increased from $22 \%$ to $30 \%$. For composites with $2 \mathrm{PW}+1 \mathrm{CSM}$ fabric, increase in short beam strength was of the order of $43 \%$. Similarly, for the other two composite panels, the increase in flexural strength was around $48 \%$.

Better tensile strength in 3PW composites is due to even stress distribution because of aligned nature of plain weave fabric. Poor strength of 3CSM composite is mainly due to anisotropic behaviour of the chopped strand mat fabric. Nonuniform stress distribution because of the presence of a chopped strand mat sandwiched between two plain weave fabrics or a plain weave mat placed in between two chopped strand mats led to inferior performance of the composite. Better wettability characteristic of chopped strand mat and greater resistance to crack propagation impart greater toughness to composites having two chopped strand mats (1PW $+2 \mathrm{CSM})$. Use of chopped strand mat increases the nesting 


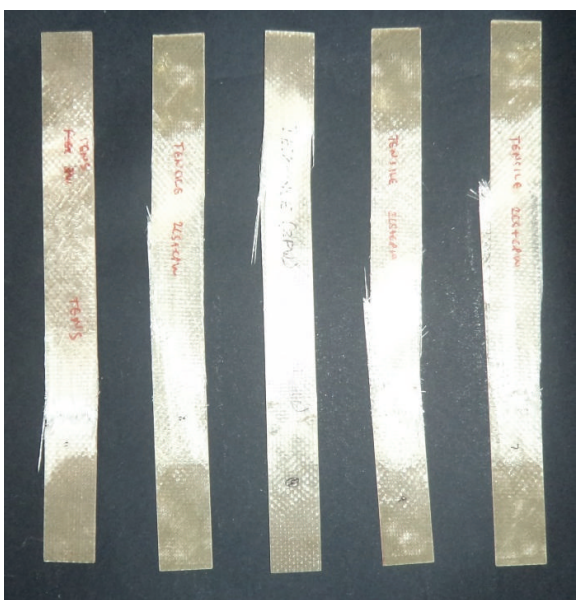

(a)

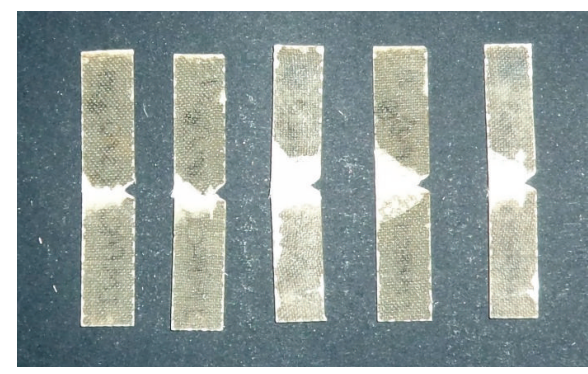

(c)

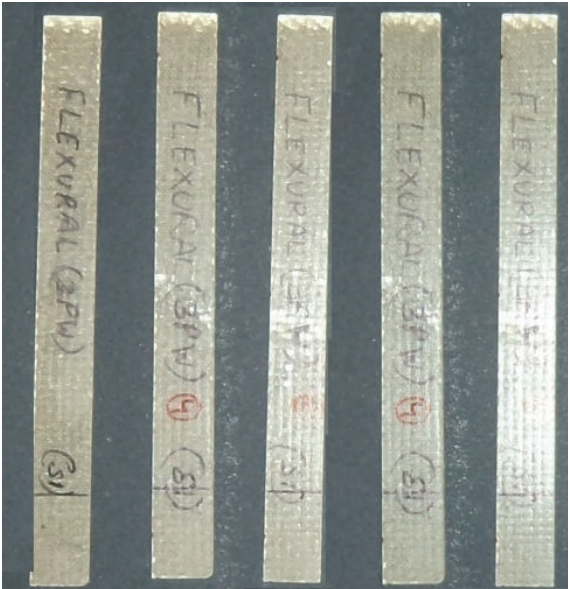

(b)

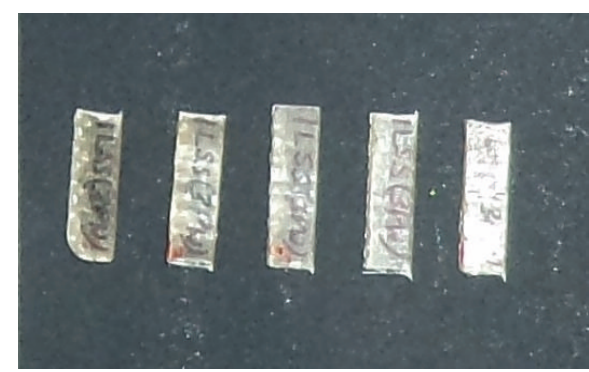

(d)

Figure 2: Test specimens. (a) Tensile, (b) flexural, (c) impact, and (d) ILSS.

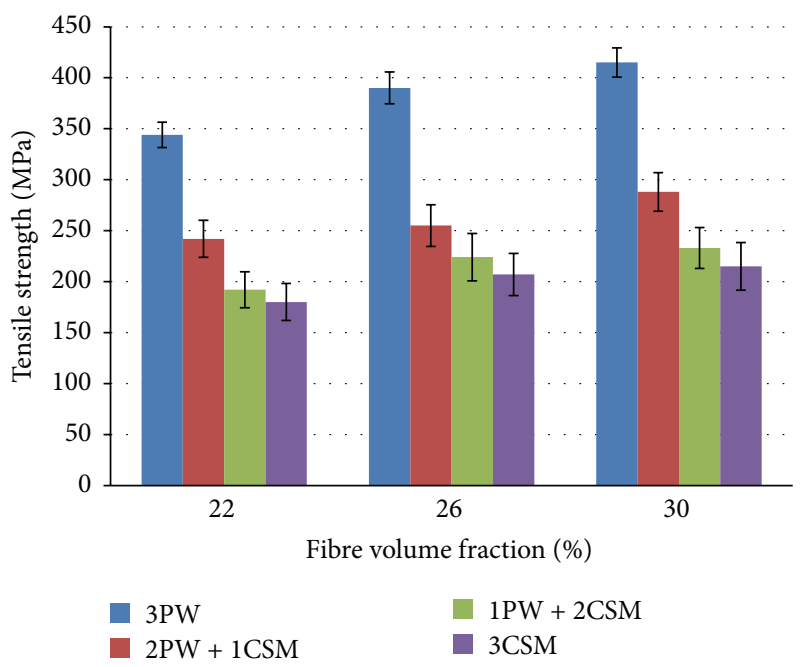

FIgURE 3: Variation in tensile strength of composites.

thus making it difficult for the crack to propagate through the layers of the fabric. Increase in impact strength in composites having two chopped strand mats may also be attributed to better bonding between layer interfaces.

3.2. Morphology of Fracture Surfaces. Micrographs of the fracture surface are shown in Figures 7-9. Only 3PW specimens were considered for morphology study. Three layers

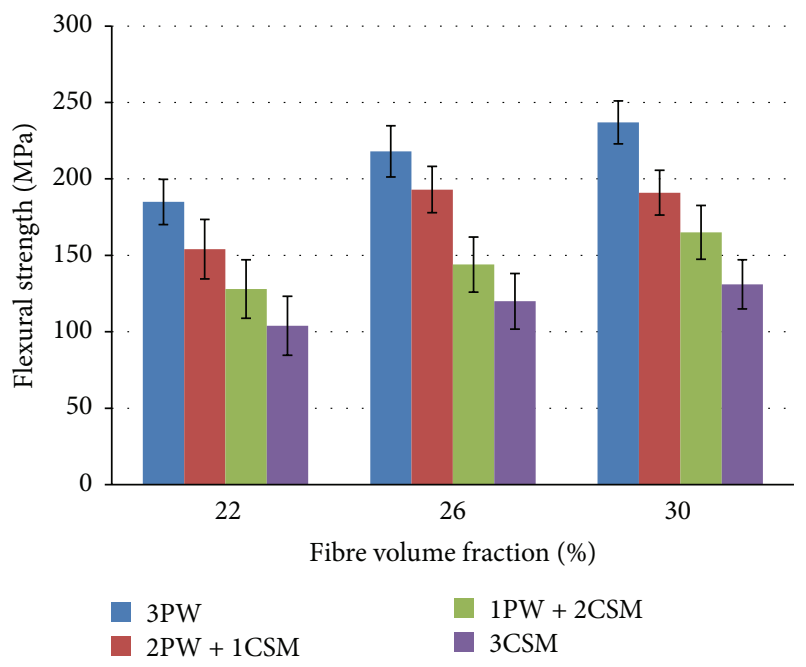

FIGURE 4: Variation in flexural strength of composites.

of PW fabric can be clearly seen in the tensile test specimen image (Figure 7). Delamination, matrix cracking, and fibre pull-out are clearly seen. Matrix cracking leads to premature failure of the specimen due to decrease in stiffness. Separation of layers due to delamination is seen in a direction perpendicular to that of loading/plane of delamination. Fracture characteristic of flexural test specimen (Figure 8) indicates 


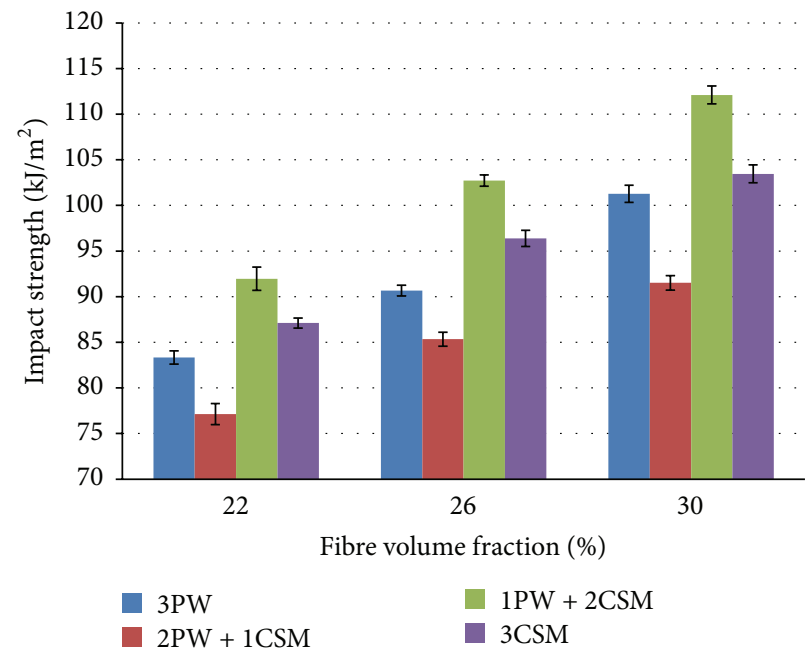

FIgURE 5: Variation in impact strength of composites.

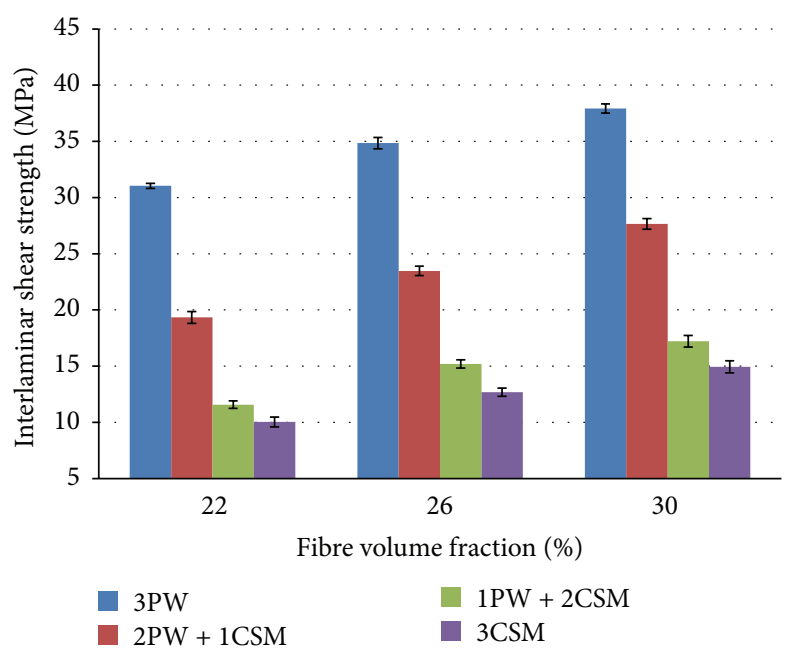

FIGURE 6: Variation in interlaminar shear strength of composites.

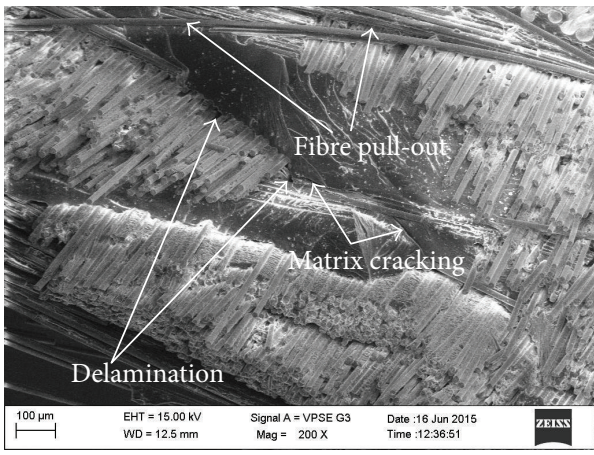

(a)

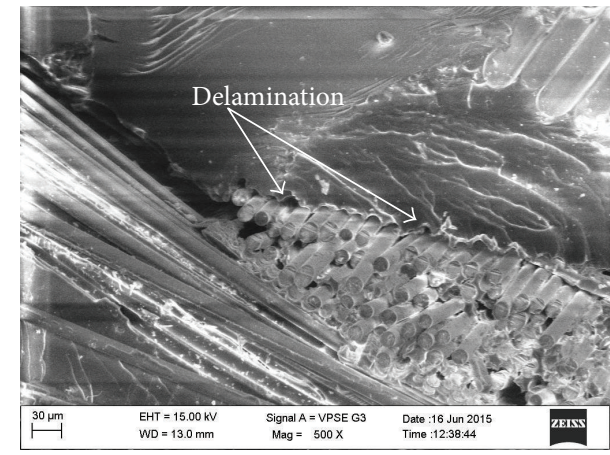

(b)

FIGURE 7: SEM image of tensile specimen. 


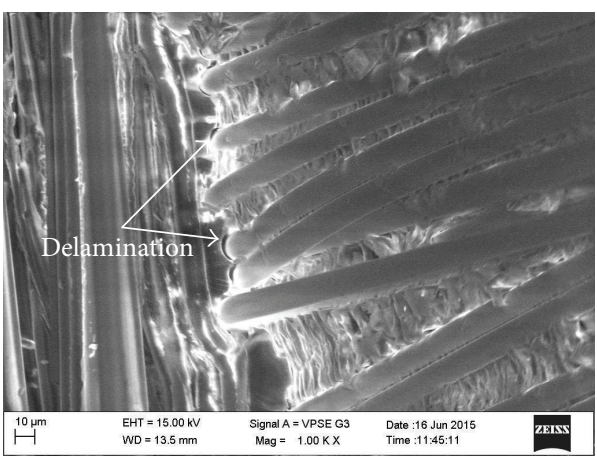

(a)

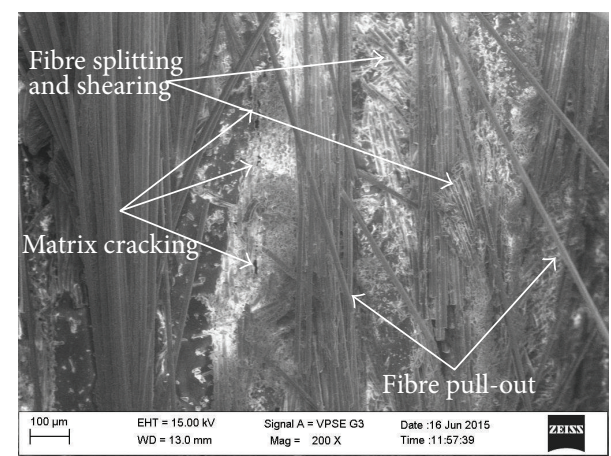

(b)

Figure 8: SEM image of flexural specimen.

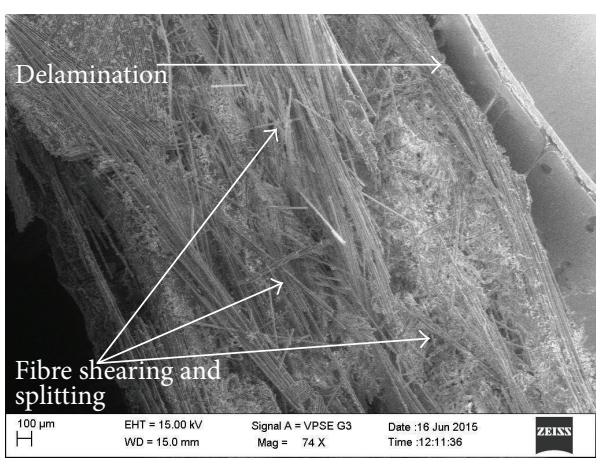

(a)

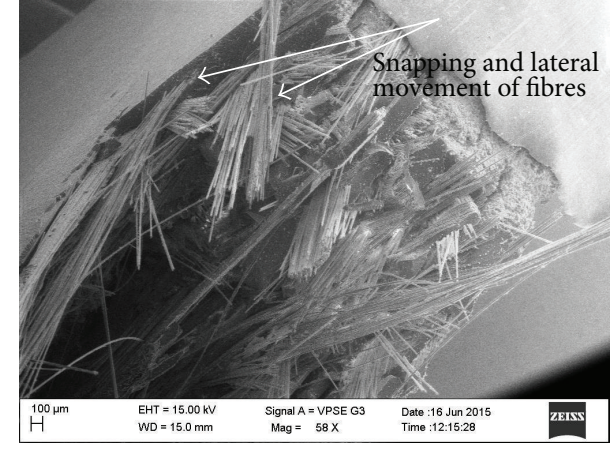

(b)

FIGURE 9: SEM image of (a) ILSS specimen, (b) impact specimen.

delamination, matrix cracking, fibre pull-out, and shearing and splitting of fibres. Shearing and splitting of fibres can also be seen in ILSS test specimen (Figure 9(a)). Fibre pull-out is an indication of deficient adhesion between the constituent materials. Snapping and lateral movement of fibres along with fibre pull-out can be seen in impact test specimen images (Figure 9(b)). Close interweaving leads to snapping rather than pushing of fibres.

\section{Conclusion}

Among all the laminates, combination of three plain weave mats demonstrated better tensile, flexural, and interlaminar shear properties. Arrangement of three chopped strand mats resulted in inferior properties except for impact strength. Maximum tensile strength of $415 \mathrm{MPa}$ was observed for tensile specimen with three layers of plain weave mats and fibre content of $30 \%$, while minimum tensile strength of $189 \mathrm{MPa}$ was seen in specimen with three chopped strand mats and $22 \%$ fibre content. Highest flexural strength of $237 \mathrm{MPa}$ was noticed in specimen with three plain weave mats and fibre content of $30 \%$ while lowest bending strength of $104 \mathrm{MPa}$ was seen in three chopped strand mats combination having a fiber volume fraction of $22 \%$. Composites with combination of one plain weave and two chopped strand mats absorbed maximum energy of $112.105 \mathrm{~kJ} / \mathrm{m}^{2}$ at fibre content of $30 \%$ while combination of two plain weave mats and one chopped strand mat absorbed the least energy of $77.141 \mathrm{~kJ} / \mathrm{m}^{2}$ at fibre content of $22 \%$. Best resistance to shear of $37.92 \mathrm{MPa}$ was seen in case of composite having fibre content of $30 \%$ and three plain weave mats while least shear strength of $10.03 \mathrm{MPa}$ was observed in composites having three chopped strand mats with fibre fraction of $22 \%$. Failure mechanisms such as fibre-matrix delamination, matrix cracking, fibre pull-out, splitting, and snapping and shearing of fibres were evident from the SEM analysis.

\section{Conflict of Interests}

The authors declare that there is no conflict of interests regarding the publication of this paper.

\section{Acknowledgments}

The authors are grateful to Dr. Divakara Shetty S., Head of the Department, Mechanical and Manufacturing Engineering, for permitting them to make use of the Advanced Material Testing and Research Laboratory. The authors thank Manipal College of Dental Sciences, Manipal, for permitting them to use material testing facilities. The authors are thankful to Dr. B. Satish Shenoy, Head of the Department, and Dr. Dayanand Pai, Professor, Department of Aeronautical and Automobile Engineering, for allowing them to use Advanced Composite and Material Testing Laboratory. The authors would also like 
to thank Dr. Raghuvir Pai B., Professor, and Dr. M Vijaya Kini, Associate Professor, Department of Mechanical and Manufacturing Engineering, for their motivation, support, and expert guidance throughout the research work.

\section{References}

[1] B. Shivamurthy, K. U. Bhat, and S. Anandhan, "Mechanical and sliding wear properties of multi-layered laminates from glass fabric/graphite/epoxy composites," Materials \& Design, vol. 44, pp. 136-143, 2013.

[2] S. Y. Nayak, S. H. Srinivas, U. S. Rao, K. Narang, and K. V. Pant, "Mechanical properties of multi layer plain weave and 3-D glass fabric epoxy composites," International Journal of Composite Materials, vol. 5, no. 2, pp. 30-36, 2015.

[3] B. Suresha, G. Chandramohan, Siddaramaiah, K. N. Shivakumar, and M. Ismail, "Mechanical and three-body abrasive wear behaviour of three-dimensional glass fabric reinforced vinyl ester composite," Materials Science and Engineering A, vol. 480, no. 1-2, pp. 573-579, 2008.

[4] K. K. Autar, Mechanics of Composite Materials, CRC Press, Boca Raton, Fla, USA, 2005.

[5] M. C. Serna Moreno and J. L. Martínez Vicente, "In-plane shear failure properties of a chopped glass-reinforced polyester by means of traction-compression biaxial testing," Composite Structures, vol. 122, pp. 440-444, 2015.

[6] M. C. Serna Moreno, J. L. Martínez Vicente, and J. J. López Cela, "Failure strain and stress fields of a chopped glass-reinforced polyester under biaxial loading," Composite Structures, vol. 103, pp. 27-33, 2013.

[7] M. Sarikanat, K. Sever, Y. Seki, and I. H. Tavman, "Mechanical anisotropy in unidirectional glass fabric reinforced oligomeric siloxane modified polyester composites," Fibers and Polymers, vol. 13, no. 6, pp. 775-781, 2012.

[8] A. M. T. Arifin, S. Abdullah, M. Rafiquzzaman, R. Zulkifli, and D. A. Wahab, "Failure characterisation in polymer matrix composite for un-notched and notched (open-hole) specimens under tension condition," Fibers and Polymers, vol. 15, no. 8, pp. 1729-1738, 2014.

[9] A. Yasar, I. Kacar, and A. Keskin, "Tensile and fatigue behavior of glass fiber-reinforced (MAT-8)/polyester automotive composite," Arabian Journal for Science and Engineering, vol. 39, no. 4, pp. 3191-3197, 2014.

[10] M. Rafiquzzaman, S. Abdullah, and A. M. T. Arifin, "Behavioural observation of laminated polymer composite under uniaxial quasi-static and cyclic loads," Fibers and Polymers, vol. 16, no. 3, pp. 640-649, 2015.

[11] S. Dolati, A. Fereidoon, and A. R. Sabet, "Experimental investigation into glass fiber/epoxy composite laminates subjected to single and repeated high-velocity impacts of ice," Iranian Polymer Journal, vol. 23, no. 6, pp. 477-486, 2014.

[12] N. S. M. El-Tayeb, B. F. Yousif, and T. C. Yap, "Tribological studies of polyester reinforced with CSM 450-R-glass fiber sliding against smooth stainless steel counterface," Wear, vol. 261, no. 3-4, pp. 443-452, 2006.

[13] S. P. Fernberg and L. A. Berglund, "Bridging law and toughness characterisation of CSM and SMC composites," Composites Science and Technology, vol. 61, no. 16, pp. 2445-2454, 2001.

[14] K. Y. Tshai, A. B. Chai, I. Kong, M. E. Hoque, and K. H. Tshai, "Hybrid fibre polylactide acid composite with empty fruit bunch: chopped glass strands," Journal of Composites, vol. 2014, Article ID 987956, 7 pages, 2014.
[15] W. Prachasaree, S. Piriyakootorn, S. Limkatanyu, and A. Hawa, "Baseline moisture resistance of PWP cement composite boards reinforced with internal glass fiber reinforcement under accelerated wet-dry aging," Journal of Composites, vol. 2014, Article ID 903497, 7 pages, 2014.

[16] A. M. T. Arifin, S. Abdullah, M. Rafiquzzaman, R. Zulkifli, D. A. Wahab, and A. K. Arifin, "Investigation of the behaviour of a chopped strand mat/woven roving/foam-Klegecell composite lamination structure during Charpy testing," Materials \& Design, vol. 59, pp. 475-485, 2014.

[17] M. M. Shokrieh, A. Saeedi, and M. Chitsazzadeh, "Evaluating the effects of multi-walled carbon nanotubes on the mechanical properties of chopped strand mat/polyester composites," Materials \& Design, vol. 56, pp. 274-279, 2014.

[18] B. Suresha, G. Chandramohan, P. R. S. Rao, P. Sampathkumaran, S. Seetharamu, and V. Venkateswarlu, "Friction and slide wear characteristics of glass-epoxy and glass-epoxy filled with SiCp composites," Indian Journal of Engineering and Materials Sciences, vol. 13, no. 6, pp. 535-541, 2006.

[19] M. Yuhazri and H. Sihombing, "A comparison process between vacuum infusion and hand lay-up method towards polyester composites," International Journal of Basic \& Applied Sciences, vol. 10, pp. 54-57, 2010.

[20] ASTM, "Standard test method for tensile properties of polymer matrix composite materials," ASTM D3039/D3039M-14, ASTM International, West Conshohocken, Pa, USA, 2014.

[21] ASTM, "Standard test method for flexural properties of polymer matrix composite materials," ASTM D7264/D7264M-07, ASTM International, West Conshohocken, Pa, USA, 2007.

[22] ASTM, "Standard test methods for determining the izod pendulum impact resistance of plastics," ASTM D256-10, ASTM International, West Conshohocken, Pa, USA, 2010.

[23] ASTM, "Standard test method for short-beam strength of polymer matrix composite materials and their laminates," ASTM D2344/D2344M-13, ASTM International, West Conshohocken, $\mathrm{Pa}, \mathrm{USA}, 2013$. 

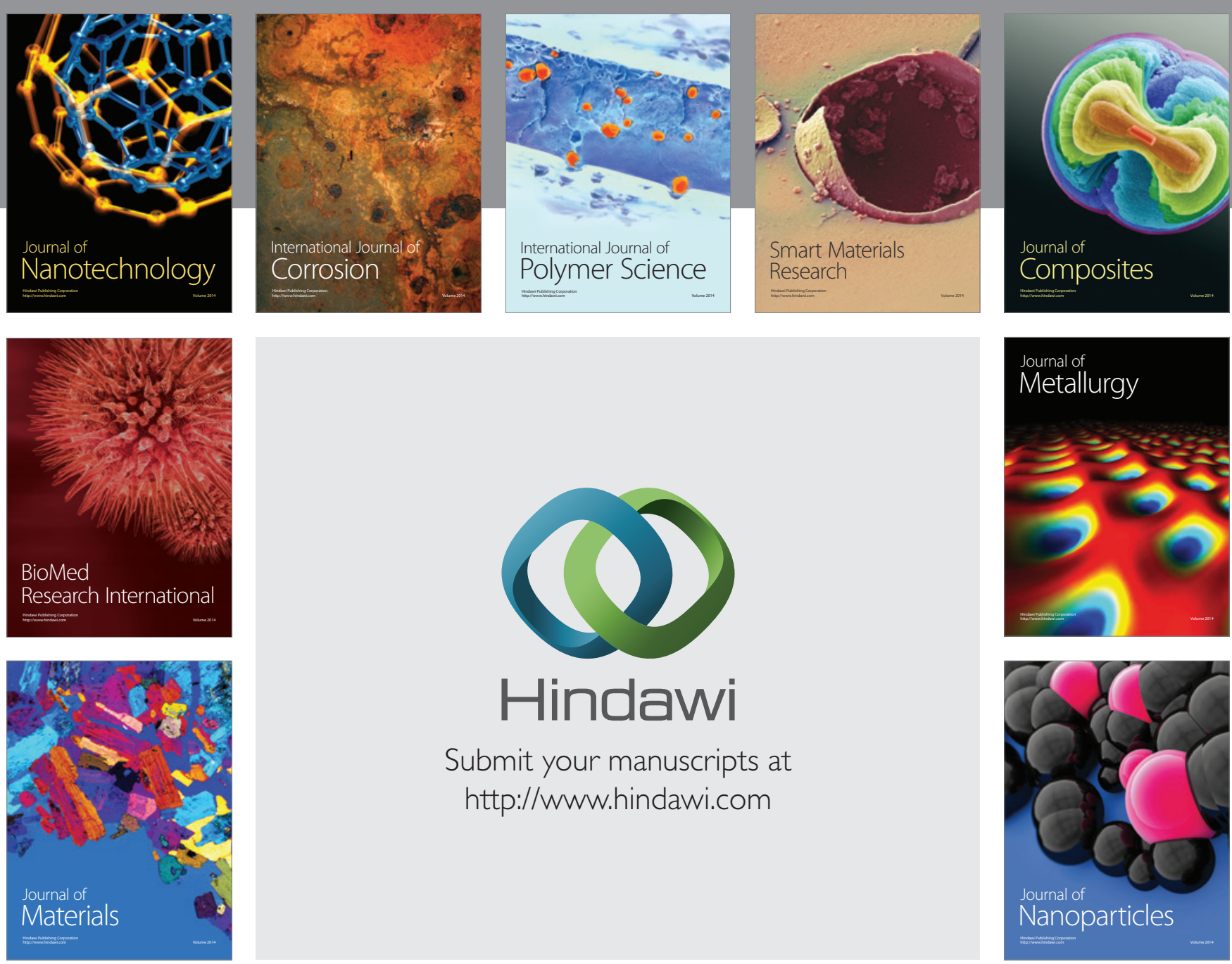

Submit your manuscripts at http://www.hindawi.com
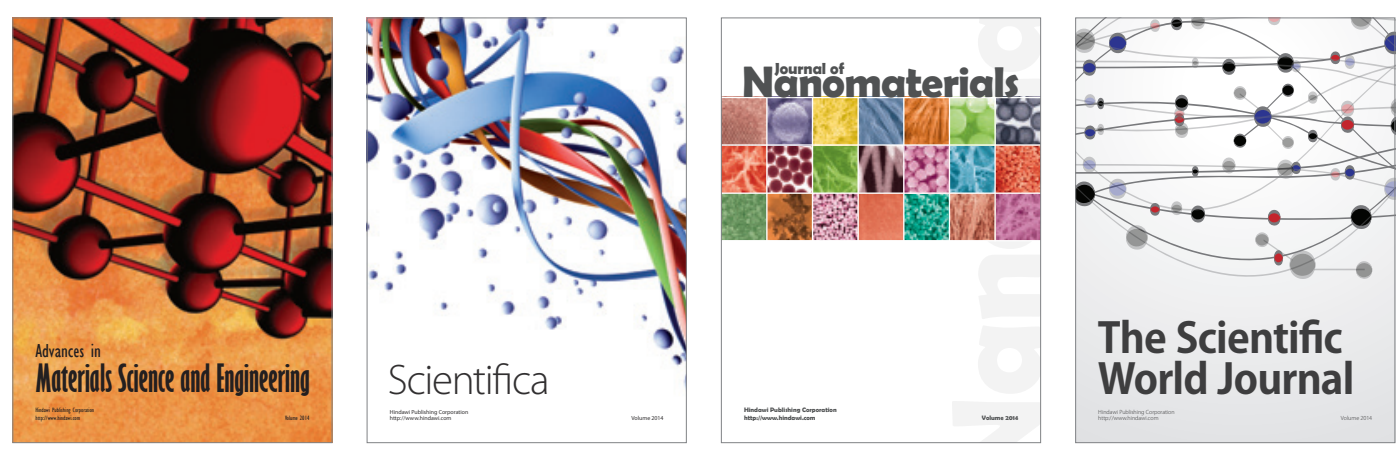

\section{The Scientific World Journal}
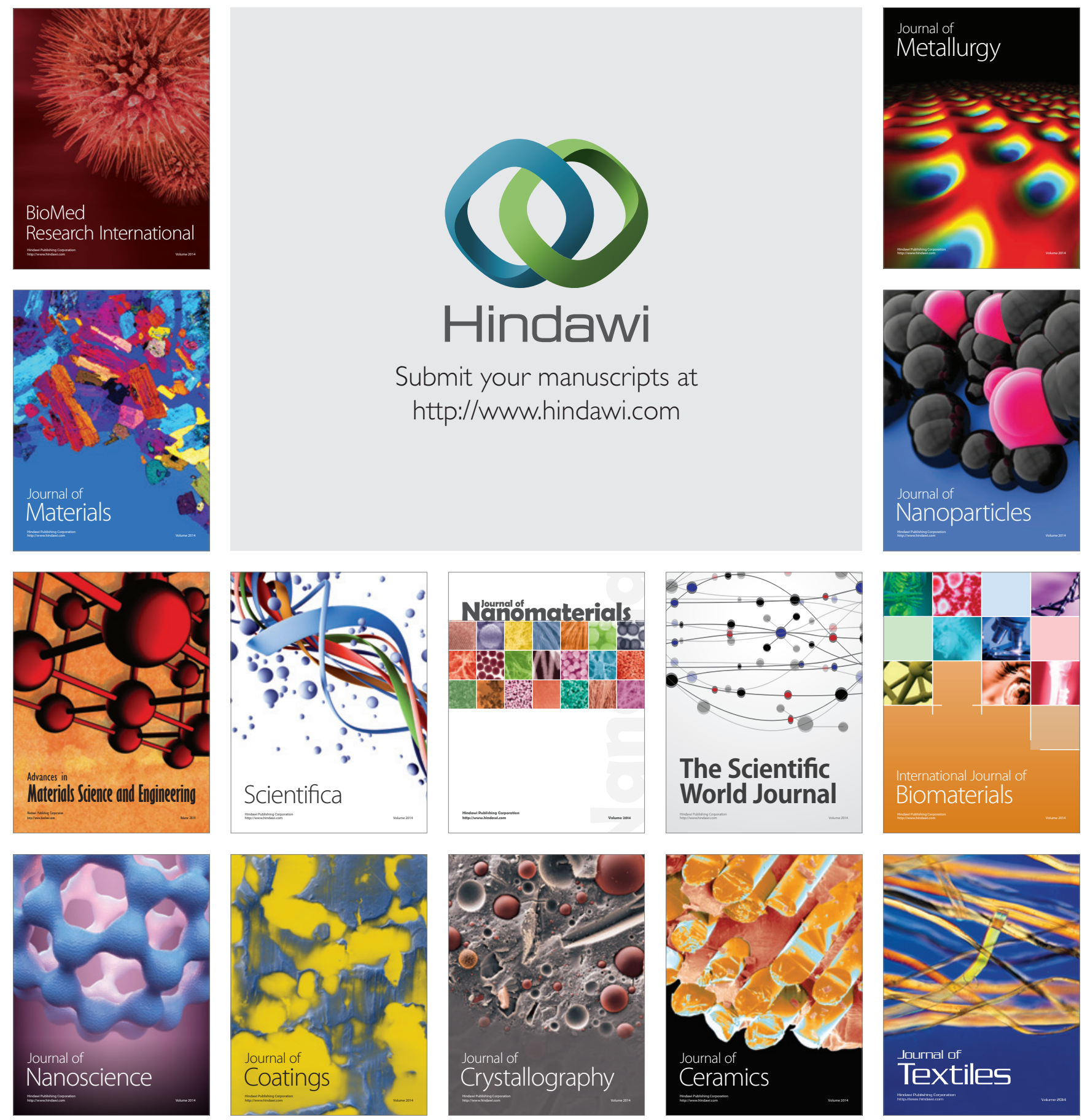